\title{
Analysis of Ductile Bursting in Pressure Vessels of Texture-Hardening and Filament-Wrapped Materials
}

\author{
Charles W. Bert \\ University of Oklahoma \\ Norman, Oklahoma 73069 \\ Also Consultant, Battelle \\ Memorial Institute, Columbus, Ohio
}

AND

WALTER S. HYLER

Battelle Memorial Institute

Columbus, Ohio 43201

\begin{abstract}
Analyses are presented for predicting the strength governed by the plastic tensile instability (PTI) phenomenon in thin-walled cylindrical and spherical pressure vessels constructed of texturehardening alloys and with or without over-wrapped filaments. These analyses are important in predicting ductile bursting of pressure vessels used in such high-performance applications as high-pressure storage bottles, liquid-propellant tankage, and solid rocket casings. The analyses cover cylindrical pressure vessels subject to any ratio of biaxial stresses. Also means of estimating the effect of finite length is presented. Spherical vessels of texturehardening material and cylindrical vessels with filaments overwrapped on a texture-hardening metallic substrate are treated as special cases. The analytical results are compared with available experimental results with good success.
\end{abstract}

\section{INTRODUCTION}

$\mathbf{A}$ PROMISING RECENT development concerning the biaxial strength of metallic materials is the concept of texture hardening, which apparently was first recognized by Backofen and his associates $[1,2]$. 
This concept consists of orienting the crystalline texture so that there are no crystallographic planes available on which slip can occur in the plane of the biaxial loading. This increases the yield strength in the plane of loading under biaxial tension, even though the uniaxial yield strength in any direction in the plane of the sheet or plate remains unchanged.

It has been shown that the hexagonal close-packed (HCP) crystalline texture, such as found in titanium and beryllium, is especially suitable for texture hardening $[1,2]$.

Using the biaxial yield strengths predicted by Hill's orthotropic plasticity theory $[3,4]$, Gerard [5] has shown the weight-saving potential of texture hardening for both spheres and long, closed-end cylinders. However, usually pressure vessels are evaluated on the basis of burst strength rather than yield strength. The experimental burst behavior of texture-hardening materials has been reported in [6-9].

As a basis for more rational material selection and for future alloy development, a theoretical analysis is needed for PTI (plastic tensile instability) in thin-walled pressure vessels made of texture-hardening material. The only such analysis known to the present authors is due to Marin and Sharma [10], but is applicable to cylinders failing due to instability of circumferential loading only. Additional analyses are presented here for axial-load tensile instability of cylinders and bursting of spheres due to internal pressure.

The benefit from using texture-hardening materials is greatest for a biaxial-stress ratio of approximately unity. Thus, Gerard [5] suggested that a very efficient pressure vesselwould result if its wall were a composite consisting of resin-impregnated glass (or boron) filaments wound circumferentially to carry one-half of the hoop load at failure and a texture-hardening metallic substrate to carry the rest of the hoop and all of the axial load at failure. This is similar to a design concept used previously $[11,12]$ with an isotropic metallic substrate.

Wolff and Harvey [13] pointed out that the biaxial-stress ratio, $B$, increases monotonically during plastic straining of the metal, so that strictly speaking, it would be necessary to use the more complicated incremental or flow theory of plasticity rather than the simpler deformation theory. However, in practice, glass filaments are wound with some prestress, which helps to keep $B$ more constant and closer to the optimal final value, $B=1$. Then analyses based on deformation plasticity theory can be used to obtain reasonably close estimates of failure performance in glass-filament-wound, metallic substrate, cylindrical pressure vessels. This has been carried out for the case of isotropic substrates by Johns and Kaufman [14]. The texture- 
hardening material analysis presented here is applied to the case of texture-hardening substrates.

\section{MATERIAL CHARACTERIZATION}

In order to characterize the mechanical behavior of the material, the following hypotheses are made:

1. Elastic strains are neglected.

2. The deformation theory of plasticity is used.

3. Rigid-plastic material behavior (i.e., constancy of material volume) is assumed.

4. The material is assumed to homogeneous.

5. The extent of plastic-range anisotropy is not altered by plastic deformation.

6. There is no hydrostatic-pressure effect on the mechanical behavior.

7. The mechanical behavior is anisotropic in such a way that the properties in the plane of the sheet are independent of orientation, while the material is textured in such a way that its properties in the thickness direction are different from those in the plane of the sheet. In other words, the material is what is known as a transversely isotropic material which is a special case of an orthotropic one. It can be shown that this is the most beneficial type of anisotropy insofar as achieving a high ratio of biaxial yield strength to uniaxial yield strength is concerned.

8. The following relation between true stress ${ }^{*}$ and true strain*, first proposed by Hollomon [15], is used:

$$
\bar{\sigma}=K \bar{\epsilon}^{n}
$$

Hypotheses 1 through 6 are the bases for Hill's theory of orthotropic plasticity $[3,4]$, while Hypothesis 7 is merely a specialization of it. $\mathrm{Hu}$ [16] and Budiansky [17] have discussed the limitations of Hypothesis 2. Alternative plasticity theories in which Hypothesis 5 is relaxed have been propounded [18-20]; in others Hypothesis 6 has

\footnotetext{
- In analyzing plastic tensile instability phenomena in reasonably ductile materials, it is necessary to use true stress and true strain rather than nominal stress and nominal strain as used in engineering design. Fortunately, the results of plastic-tensile-instability analyses can be converted back to nominal quantities for design use. True stress is simply the instantaneous Ioad divided by the instantaneous cross-sectional area. At tension plastic strains, the stress is always greater than the nominal stress, which is the load divided by the original cross-sectional area. True strain, sometimes called logarithmic strain, is equal to the natural logarithm of the ratio of the instantaneous gage strain, sometimes called logarithmic strain, is equal to the natural logarithm of the ratio of the instantaneous gage distributed). Nominal strain is merely the ratio of the change in length to the original length.
} 


\section{Analysis of Ductile Bursting in Pressure Vessels}

been relaxed $[21,22]$. It has been shown recently that Hypotheses 1 and 3 have a negligible effect on the stress at which plastic tensile instability occurs [23]. In short, the hypotheses used here are reasonable on the basis of the current state of the art of plasticity theory.

The material parameter first suggested by Backofen et al [1], to characterize the anisotropy of a transversely isotropic, texturehardened material is the following true strain ratio:

$$
R \equiv d \epsilon_{\text {width }} / d \epsilon_{\text {thickness }}
$$

Larson [24] has suggested that the plastic-range Poisson's ration $\mu_{p}$ associated with in-plane deformation be used as a measure of texturehardening anisotropy. It can be shown that $\mu_{p}$ and $R$ are related by

$$
\mu_{p}=R /(1+R)
$$

Since strength is of more direct importance in ductile failure than strain, the following strength ratio has been proposed as a more significant measure of texture-hardening capability [25]:

$$
\alpha=\sigma_{z y} / \sigma_{p y}
$$

where $\sigma_{z y}$ and $\sigma_{p y}$ are the respective yield strengths in the thickness direction and in the plane of the sheet. The ratios $\alpha$ and $R$ are related by the following expression:

$$
\alpha=[(1+R) / 2]^{1 / 2}
$$

Table 1 lists values of $R, \mu_{p}$, and $\alpha$ determined experimentally for

\begin{tabular}{|c|c|c|c|c|}
\hline Alloy & Ref. & $\begin{array}{l}\text { Strain } \\
\text { Ratio R }\end{array}$ & $\begin{array}{l}\text { Plastic } \\
\text { Poisson's } \\
\text { Ratio } \mu_{p}\end{array}$ & $\begin{array}{c}\text { Stress } \\
\text { Ratio } \alpha\end{array}$ \\
\hline Ti-4Al-3Mo-1V & 26 & 7.20 & 0.88 & 2.02 \\
\hline Ti-4AI & 27 & $1.18-6.2$ & $0.54-0.86$ & $1.04-1.90$ \\
\hline Ti-4AI & 34 & $6.8-7.0$ & $0.87-0.88$ & $1.97-2.00$ \\
\hline Ti-4Al-4Mn & 6 & $4.0-5.5$ & $0.80-0.85$ & $1.58-1.80$ \\
\hline Ti-5Al-2.5Sn & 27 & $1.18-3.3$ & $0.54-0.77$ & $1.18-1.47$ \\
\hline Ti-5Al-2.5Sn & 6 & $2.20-3.54$ & $0.69-0.78$ & $1.26-1.51$ \\
\hline Ti-5Al-2.5Sn & 24 & $2.33-9.0$ & $0.70-0.90$ & $1.29-2.24$ \\
\hline Ti-5Al-2.5Sn & 8,9 & $2.00-3.03$ & $0.67-0.75$ & $1.22-1.42$ \\
\hline Ti-5Al-2.5Sn & 34 & $0.82-3.2$ & $0.45-0.76$ & $0.95-1.45$ \\
\hline Ti-6Al-4V & 26 & 3.62 & 0.78 & 1.52 \\
\hline Ti-6Al-4V & 27 & $0.5-1.2$ & $0.33-0.55$ & $0.87-1.05$ \\
\hline Ti-6Al-4V & 24 & $0.16-3.03$ & $0.14-0.75$ & $0.76 \cdot 1.42$ \\
\hline Ti-6Al-4V & 34 & $0.67-4.0$ & $0.40-0.80$ & $0.91-1.58$ \\
\hline
\end{tabular}
some titanium alloys $[6,8,9,24,26,27,34]$.

Table 1. Values of Texture-Hardening Parameters $R, \mu_{p}$, and $\alpha$ Obtained with Various Titanium Alloys 
The stress-strain relations for biaxial loading can be expressed as:

$$
\begin{aligned}
& \epsilon_{\theta}=(\bar{\epsilon} / \bar{\sigma})\left[\sigma_{\theta}-\left(1-\alpha^{-2} / 2\right) \sigma_{a}\right], \\
& \epsilon_{a}=(\bar{\epsilon} / \bar{\sigma})\left[\sigma_{a}-\left(1-\alpha^{-2} / 2\right) \sigma_{\theta}\right], \\
& \epsilon_{r}=-(\bar{\epsilon} / \bar{\sigma})\left(\alpha^{-2 / 2}\right)\left(\sigma_{\theta}+\sigma_{a}\right)
\end{aligned}
$$

where $\bar{\sigma}$ is the effective true stress defined by the following expression:

$$
\bar{\sigma}^{2}=\sigma_{\theta}^{2}+\sigma_{a}^{2}-\left(2-\alpha^{-2}\right) \sigma_{\theta} \sigma_{a}
$$

Biaxial yield-strength envelopes for an isotropic material $(\alpha=1)$ and for a typical texture-hardening material $(\alpha=1.36)$ are given in Figure 1.

\section{GEOMETRICAL AND LOADING CONSIDERATIONS}

The following additional hypotheses are made:

1. The shell geometry is that of a circular cylinder or a sphere.

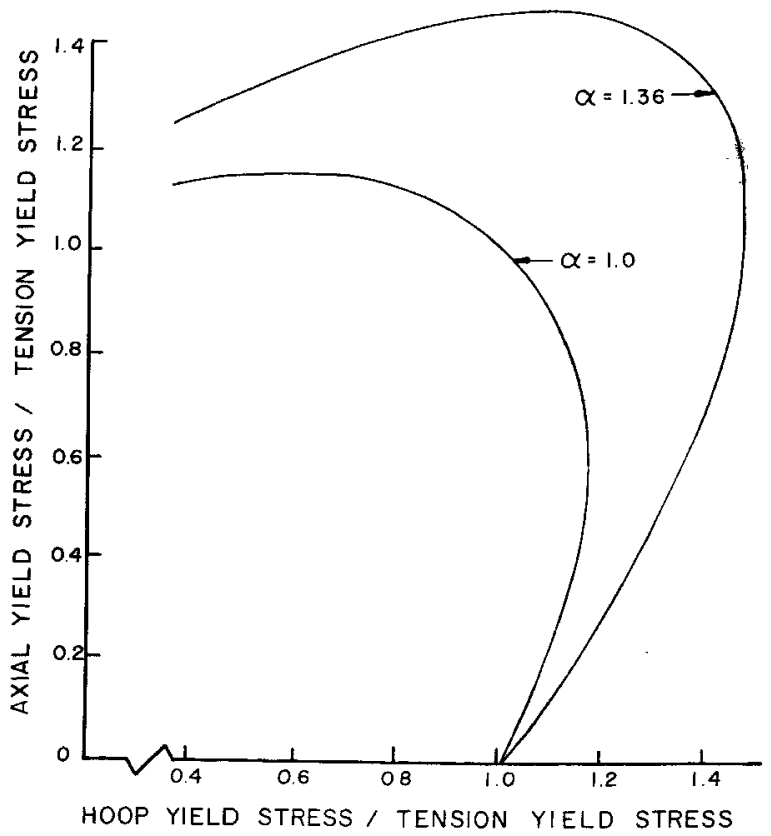

figure 1. Biaxial yield-stress envelopes for an isotropic material $(\alpha=1)$ and for a texture-hardening material $(\alpha=1.36)$. 
2. The shell is thin-walled; i.e., the wall thickness is very small in comparison to the shell radius so that the thickness-direction stress is negligible.

3. It is assumed that no bending action takes place until the onset of tensile instability. This implies that in the case of the cylinder, it must be long so that the girdle-type restraint of the end closures is negligible.

4. The loadings considered are: for the sphere, uniform internal pressure only; for the cylinder, uniform internal pressure and external axial tension or compression, combined in any way so as to give any positive biaxial-stress ratio.

\section{TENSILE INSTABILITY IN CYLINDERS DUE TO HOOP LOAD}

For the case when plastic tensile instability in a long, thin-walled cylinder is governed by hoop load, the analysis of [10] for an orthotropic cylinder can be adapted to the more specialized case of a transversely isotropic, texture-hardening material by making the following transformations of the orthotropic parameters:

$$
\alpha_{11} \rightarrow 1, \alpha_{12} \rightarrow 1-\alpha^{-2} / 2, \alpha_{22} \rightarrow 1, \alpha_{31} \rightarrow \alpha^{-2} / 2, \alpha_{23} \rightarrow \alpha^{-2 / 2}
$$

Then the result is

$$
S_{\theta i} / S_{t u}=\left[1-\left(2-\alpha^{-2}\right) B+B^{2}\right]^{(n-1) / 2}\left[\left(1+\alpha^{-2} / 2\right)-\left(1-\alpha^{-2}\right) B\right]^{-n}
$$

where $B \equiv \sigma_{a} / \sigma_{\theta}, S_{t u}$ is the nominal ultimate tensile strength (uniaxial in the plane of the sheet) assuming that uniaxial failure occurs by plastic tensile instability, and $S_{\theta i}$ is the nominal hoop stress in the cylinder at plastic tensile instability.

Table 2 summarizes all of the experimental results available to the authors on hydrotests of thin-walled vessels made of texturehardening materials. All of the vessels were cylindrical and all of the materials were titanium alloys. The comparisons between the experimental results and calculations using (8) are inconclusive in the instance of two series of tests: In both of the Series 1 tests, failure did not occur as a result of plastic tensile instability, since in both tests failure occurred prematurely at the longitudinal welds; also in the Series 6 tests, the exact value of the texture-hardening parameter $\alpha$ (or $R$ or $\mu_{p}$ ) was not known and thus had to be estimated on the basis of measurements made at another laboratory on specimens probably from another heat and made by another producer. However, in the Series 2 through 5 tests, failure was apparently quite ductile and thus 
Table 2. Comparison of Hoop Failure Stresses Determined Experimentally and By Calculation for Texture-Hardening Titanium-Alloy Cylinders

\section{Experimental Results}

\begin{tabular}{|c|c|c|c|c|c|c|c|}
\hline \multirow{2}{*}{$\begin{array}{c}\text { Test } \\
\text { Series }\end{array}$} & \multirow[b]{2}{*}{ Material } & \multirow[b]{2}{*}{ Ref. } & \multirow[b]{2}{*}{$\alpha$} & \multirow[b]{2}{*}{ B } & \multirow{2}{*}{$\begin{array}{c}\text { No. of } \\
\text { Specimens }\end{array}$} & \multicolumn{2}{|c|}{$\begin{array}{l}\text { Mean Hoop } \\
\text { Failure Stress }\end{array}$} \\
\hline & & & & & & $\mathbf{s}_{\theta i}, \mathbf{k s i}$ & $\boldsymbol{S}_{\theta i} / \boldsymbol{S}_{t u}$ \\
\hline 1 & Ti-5Al-2.5Sn & 6 & 1.4 & 0.5 & 2 & $155^{* * *}$ & $1.17^{* * *}$ \\
\hline 2 & " & 8,9 & 1.36 & 0.53 & 4 & 201 & 1.54 \\
\hline 3 & $"$ & 8,9 & 1.36 & 0.90 & 5 & 224 & 1.71 \\
\hline 4 & $"$ & 8,9 & 1.36 & 1.24 & 1 & 222 & 1.69 \\
\hline 5 & $"$ & 34 & 1.33 & 0.485 & 2 & 165 & 1.40 \\
\hline 6 & Ti-6Al-4V & 7 & $1.3^{*}$ & 0.5 & 3 & 196 & 1.33 \\
\hline
\end{tabular}

Calculated Results

\begin{tabular}{|c|c|c|c|}
\hline \multirow[b]{2}{*}{ Series } & \multirow{2}{*}{$\begin{array}{c}\text { Estimated } \\
n\end{array}$} & \multicolumn{2}{|c|}{$\mathbf{S}_{\theta i} / \mathbf{S}_{t u}$} \\
\hline & & LC & $F L$ \\
\hline 1 & 0.095 & 1.36 & - \\
\hline 2 & $"$ & 1.36 & 1.50 \\
\hline 3 & $"$ & 1.39 & 1.50 \\
\hline 4 & $"$ & 1.19 & 1.29 \\
\hline 5 & $"$ & 1.32 & 1.35 \\
\hline 6 & 0.070 & 1.32 & - \\
\hline
\end{tabular}

* Estimated on the basis of data presented in Table 1.

** Failure occurred prematurely in the longitudinal weld in both specimens.

C...

undoubtedly due to plastic tensile instability.

In the Series 2 through 5 tests, the values calculated by (8) and labeled LC in Table 2 fall from approximately 6 to 30 percent below the values obtained experimentally. This is unusual in plastic tensile instability experimental-calculated comparisons, where it has been found that the calculated values usually exceed the experimental values by from 1 to 15 percent [10].

In attempting to determine the cause for this discrepancy, there are at least three potential explanations:

1. The girdle-type radial and rotational restraint offered by the end closures on the actual finite-length cylinders, which is neglected in the theoretical analysis.

2. A hydrostatic pressure effect.

3. An effect whereby the texture-hardening effect (as characterized by $\alpha$, for example) increases with plastic strain during loading. 


\section{Analysis of Ductile Bursting in Pressure Vessels}

The length-to-diameter ratio of the cylinders used in the Series 2 through 4 tests is $L / D=0.96$ if only the main (uniform-thickness) cylindrical portion is considered, or $L / D=1.37$ if the tapered cylindrical transition sections are also included. Empirical results reported by Sachs et al [28], indicate that closed-end alloy steel cylinders subject to internal pressure $(B=1 / 2)$ tend to burst at stresses 6 to 12 percent above those of infinitely long cylinders, for these finite $L / D$ ratios. However, the titanium alloys of interest here have lower strainhardening exponents and thus a smaller difference. Thus, results of theoretical analyses must be used. For example, the analysis of Weil et al [29], predicts an increase of approximately 4 to 8 percent.

Unfortunately, no analysis of the effect of finite $L / D$ on texturehardening materials appears to be available. However, to indicate the order of magnitude of the effect, a very approximate estimate can be made by considering a spherical shell to be the upper bound for the girdle effect, i.e., a cylinder with $L / D=0$ and hemispherical end caps. Since the nominal hoop stress for a spherical shell is one-half that of a cylindrical shell,

$$
\left(S_{\theta i}\right)_{o L} / S_{t u}=2\left(S_{\theta i}\right)_{s p h} / S_{t u}
$$

where subscripts $O L \sim$ zero-length cylinder and $s p h \sim$ spherical. An expression for $\left(S_{\theta i}\right)_{s p h} / S_{t u}$ is given by (27). Then the following interpolation formula is used to interpolate between a long cylinder and a zero-length cylinder (sphere):

$$
x_{F L}^{\prime}=x_{L C}^{\prime}+\left(\frac{x_{F L}-x_{L C}}{x_{O L}-x_{L C}}\right)\left(x_{o L}^{\prime}-x_{L C}^{\prime}\right)
$$

where $x \equiv S_{\theta i} / S_{t u}$, the unprimed quantities denote the isotropic case, the primed quantities denote the texture-hardening case, and the subscripts are as follows: $L C \sim$ long cylinder, $O L \sim$ zero-length cylinder, $F L \sim$ finite-length cylinder.

The results of applying (9) and (10) to the Series 2 through 5 test cylinders is given in Table 2 in the column labeled $F L$. These interpolated values still fall from approximately 2 to 24 percent below the experimental values.

This rough interpolation indicates that the finite-length effect cannot account for the high experimental burst strengths. However, recent research [32] indicates that the texture-hardening effect increases with plastic strain. In their example, the plastic strain ratio $R$ increased from 2.31 at 0.2 percent MPOS (maximum principal offset strain) to 4.83 at 0.8 percent MPOS and finally to 5.90 at burst. This same phenomenon of increasing anisotropy (increasing $R$ ) with in- 
creasing biaxial loading has also been observed in tests using flat sheet material with face grooves [33]. This is in contradiction to Hypothesis 5 and Hill's orthotropic plasticity theory and will require additional research to resolve.

\section{TENSILE INSTABILITY IN CYLINDERS DUE TO AXIAL LOAD}

The total axial load $P_{a}$, which is the sum of the external load and the pressure load $\pi r^{2} p$, is related to the axial stress as follows:

$$
P_{a}=2 \pi r h \sigma_{a}
$$

Setting the total differential $d P_{a}=0$ and noting that

$$
d r / r=d \epsilon_{\theta}, d h / h=d \epsilon_{r}
$$

one arrives at the following expression, which has been obtained previously by Felgar [30]:

$$
d \sigma_{a i} / \sigma_{a i}=-d \epsilon_{\theta i}-d \epsilon_{r i}
$$

From (6), it is noted that $\epsilon_{a} / \epsilon_{\theta}$ remains at a constant value (denoted by $C_{1}$ ) for a given $\alpha$ and $B$. Then constancy of material volume requires that $d \epsilon_{r} / d \epsilon_{\theta}=\epsilon_{r} / \epsilon_{\theta}=-\left(1+C_{1}\right)$. Putting these results into (13) yields:

$$
d \sigma_{a i} / d \epsilon_{a i}=\sigma_{a i}
$$

Making use of (1), (6), and (7), it is found that

where

$$
\sigma_{a}=K\left(\epsilon_{a} / C_{2}\right)^{n}
$$

$$
C_{2} \equiv\left[1-\left(2-\alpha^{-2}\right) B^{-1}+B^{-2}\right]^{(1-n) / 2 n}\left[1-\left(1-\alpha^{-2} / 2\right) B^{-1}\right]
$$

Taking the derivative of (15) yields:

$$
d \sigma_{a} / d \epsilon_{a}=n \sigma_{a} / \epsilon_{a}
$$

Equating the right-hand sides of (14) and (17) gives the following expression for the axial true strain at which tensile instability takes place:

$$
\epsilon_{a i}=n
$$

It is noted that this is exactly the same value of true strain at which uniaxial tensile instability occurs. However, the corresponding nominal stresses are quite different in the two cases due to the difference in the stress states. 
From (15) and (18),

$$
\sigma_{a i}=K\left(n / C_{2}\right)^{n}
$$

The nominal axial stress is defined here as follows:

$$
S_{a}=P_{a} / 2 \pi r_{o} h_{o}
$$

where $r_{o}$ and $h_{o}$ are the initial values of $r$ and $h$. Then combining (11), (12), (19), and (20), yields the following expression for the nominal axial stress at which tensile instability occurs:

$$
S_{a}=K\left(n / C_{2} e\right)^{n}
$$

where $e$ is the base of the natural logarithms.

From uniaxial tensile instability theory, as given by Marin [31] for example, the nominal ultimate tensile strength is

$$
S_{t u}=K(n / e)^{n}
$$

From (16), (21), and (22), the following dimensionless result is obtained:

$$
S_{a i} / S_{t u}=\left[1-\left(2-\alpha^{-2}\right) B^{-1}+B^{-2}\right]^{(n-1) / 2}\left[1-\left(1-\alpha^{-2} / 2\right) B^{-1}\right]^{-n}
$$

For the case of uniaxial loading in the axial direction $(B \rightarrow \infty),(23)$ gives a result of unity, which serves as a check.

Figure 2 shows a biaxial-ultimate-strength envelope for two materials, each having the same value of the strain-hardening exponent $(n=0.095)$ : One material is isotropic $(\alpha=1)$ and the other is of the texture-hardening type with $\alpha=1.36$. The transitional biaxialstress ratio at which the plastic tensile instability phenomenon changes from hoop to axial (shown as dashed lines in Figure 2) is found by equating $S_{a i}=B S_{\theta i}$, using values from (8) and (23) for $S_{\theta i}$ and $S_{a i}$, respectively. The result is:

$$
B_{\text {trans }}=2 /\left(2-\alpha^{-2}\right)
$$

\section{TENSILE INSTABILITY IN PRESSURIZED SPHERES}

For a thin-walled sphere subject to uniform internal pressure $p$, the in-surface stresses are given by

$$
\sigma_{\theta}=p r / 2 h
$$

Then setting $d p=0$ for instability and using relations (12) which are applicable to spheres as well as cylinders, the following result is 


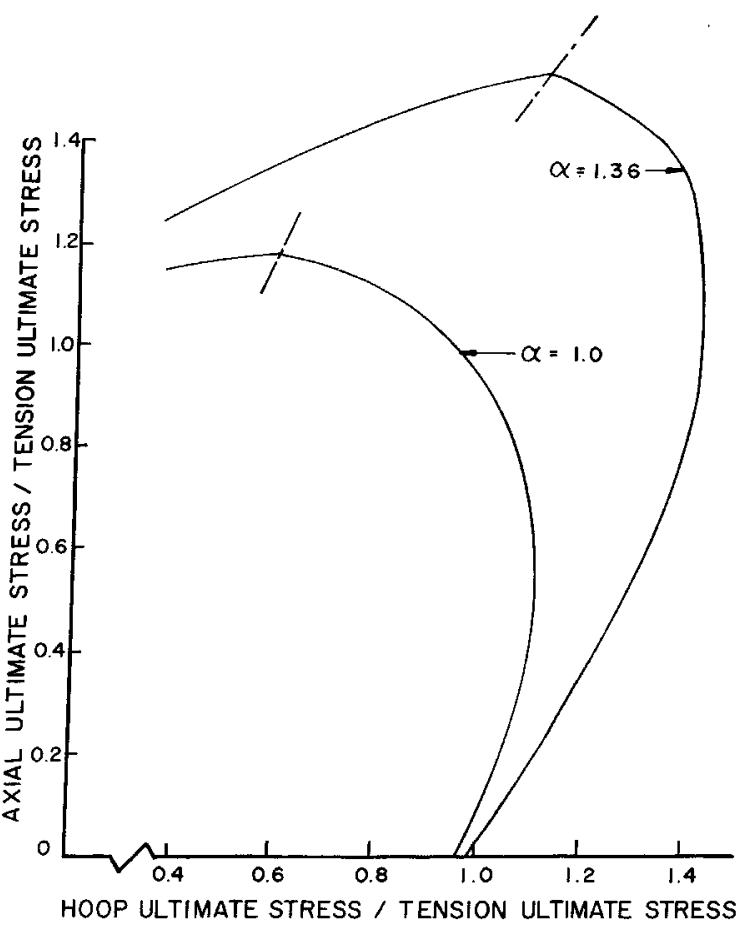

Figure 2. Biaxial ultimate-stress envelopes for two materials with a strain-hardening exponent of 0.095: isotropic $(\alpha=1)$ and texture-hardening ( $\alpha=1.36$ ).

obtained:

$$
d \sigma_{\theta i} / \sigma_{\theta i}=d \epsilon_{\theta i}-d \epsilon_{r i}
$$

Since (26) is identical to that obtained by Marin and Sharma as an intermediate step in their analysis of the hoop-direction tensile instability in a cylindrical shell, the same analysis is applicable here provided the correct biaxial-stress ratio $(B=1)$ is used. Thus, the result is (8) with $B=1$ :

$$
\left(S_{\theta i}\right)_{s p h} / S_{t u}=(2 / 3)^{n} \alpha^{1+n}
$$

Although expression (27) for the sphere stress ratio $S_{\theta} / S_{t u}$ is identical to that for a long cylinder subject to the same biaxial stress ratio $(B=1)$, the nominal hoop stress per unit pressure $\left(S_{\theta} / p\right)$ for a sphere is $r_{o} / 2 h_{o}$, while for a long cylinder it is twice that, namely $r_{o} / h_{o}$. Thus, according to the theory presented, a sphere can withstand twice the burst pressure of a long cylinder of the same radius, thickness, and material at $B=1$. 


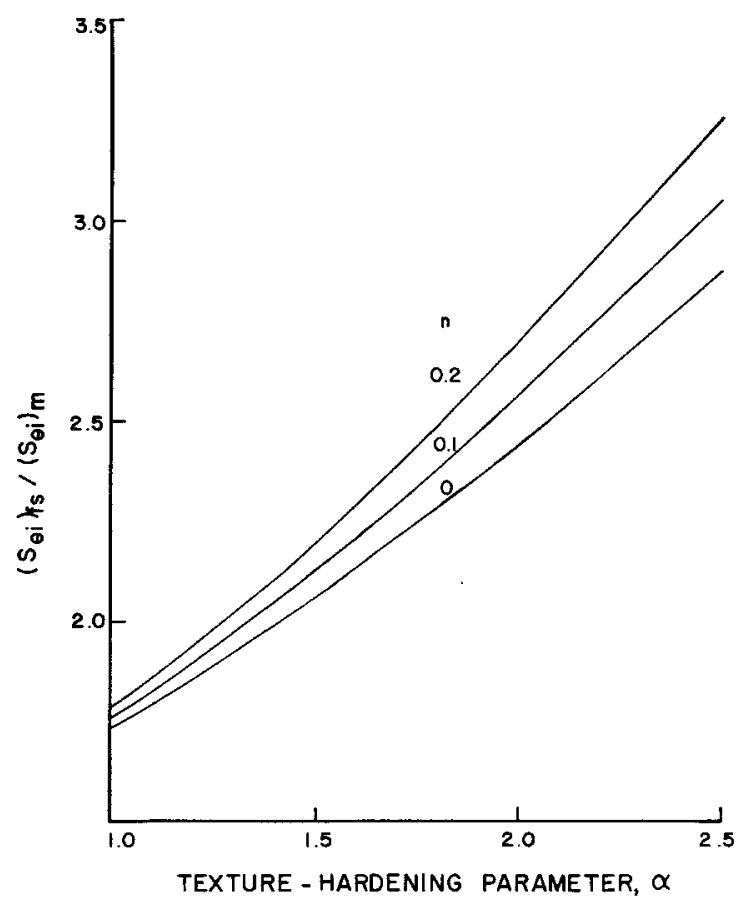

Figure 3. Ratio of hoop stress at burst for a glass filament/metallic substrate cylinder to that for a monolithic cylinder of the same alloy versus texture-hardening parameter $\alpha$ for selected values of strain-hardening exponent $n$.

\section{APPLICATION TO FILAMENT-OVERWRAPPED METALLIC-SUBSTRATE CYLINDERS}

To compare performance of closed-end cylindrical pressure vessels, it is desirable to calculate the ratio of the hoop strength of the substrate (at tensile instability) for the filament/substrate composite cylinder, $\left(S_{\theta i}\right)_{f s}$, to that of a monolithic cylinder constructed entirely of the same material as the substrate, $\left(S_{\theta i}\right)_{m}$. Using the design philosophy that the filaments should carry one-half of the hoop load at failure and assuming that there is adequate prestress, this ratio can be expressed as:

$$
\left(S_{\theta i}\right)_{f s} /\left(S_{\theta i}\right)_{m}=2\left(S_{\theta i}\right)_{B=1} /\left(S_{\theta i}\right)_{B=1 / 2}
$$

Using (8), (28) becomes

$$
\left(S_{\theta i}\right)_{f s} /\left(S_{\theta i}\right)_{m}=(2 / 3)^{n} \alpha^{1+n}\left(1+2 \alpha^{-2}\right)^{(1+n) / 2}
$$

The relationship expressed by (29) is depicted graphically in Figure 3. As can be seen, the texture-hardening parameter $\alpha$ is much 
more dominant than the strain-hardening exponent $n$.

Since all of the filament-overwrapped cylindrical pressure vessels known to the present investigators have been made with isotropic substrate materials, no comparisons can be made between theory and experiment for texture-hardening substrate materials. However, the mean values of the burst-strength ratios obtained experimentally by various investigators for several different isotropic substrate alloys, as listed in Table 3, agree well with the theoretical range of 1.73 to 1.78 for $\alpha=1.0$ and $n$ ranging from 0 to 0.2 with one exception.

\section{SUMMARY}

Plastic tensile instability (PTI) analyses were presented for cylindrical and spherical pressure vessels of texture-hardening alloys with or without overwrapped filaments. On the basis of these analyses and comparison of the results with experimental results, these conclusions were drawn:

1. The cylindrical pressure-vessel analysis presented covers all possible biaxial-stress ratios at which PTI governs. Even when corrected for finite length, the calculated values of hoop stress at failure were always conservative (i.e., low) compared to the experimental values for certain texture-hardening titanium alloys. In all cases, ranging in biaxial-stress ratio $B$ from 0.5 to 1.24 , the ratios of hoop failure stress to ultimate tensile strength were substantially greater than they would be for a ductile isotropic material.

2. The transitional biaxial-stress ratio at which PTI occurs simultaneously in both the axial and hoop directions was substantially lower for texture-hardening material than for an isotropic one. However, this does not reduce the increased load-carrying capacity of texture-hardening materials in the range of $B$ from approximately 0.5 to 2.0 .

Table 3. Experimentally Measured, Room-Temperature BurstStrength Ratios for Cylindrical Pressure Vessels Having Isotropic Metallic Substrates Overwrapped with Glass Filaments

\begin{tabular}{ccc}
\hline Substrate Alloy & Reference & $\begin{array}{c}\text { Mean Value of } \\
\left(\boldsymbol{S}_{\theta i}\right)_{f s} /\left(\mathrm{S}_{\theta i}\right)_{m}\end{array}$ \\
\hline $7178-\mathrm{T6} \mathrm{Al}$ & 12 & 1.77 \\
" & 11 & 2.07 \\
$2014-\mathrm{T} 6 \mathrm{Al}$ & 14 & 1.67 \\
SAE 4130 Steel & 13 & 1.74
\end{tabular}


3. It was shown that the nominal hoop stress at PTI failure for a spherical shell subject to internal pressure is the same as that for a long cylindrical shell of the same radius, thickness, and material and subject to the same biaxial-stress ratio $(B=1)$, just as in the case of isotropic material.

4. Application of the theory to prediction of PTI failure of isotropic metallic cylindrical pressure vessels overwrapped with glass filaments gave results which agreed fairly well with experimental results.

5. Since to the authors' knowledge, no texture-hardening substrate/glass-filament-wrapped pressure vessels have been built to date, the theory could not be verified for this case. However, due to the good agreement mentioned above, it is believed that the theory gives a reliable prediction. The theory confirms Gerard's prediction (which was based on biaxial yield stress only) that such a pressure vessel should be a very efficient one from the standpoint of pressurevessel performance/weight efficiency.

\section{NOMENCLATURE}

$B=$ ratio of biaxial principal true stresses, $\sigma_{a} / \sigma_{\theta}$

$C_{1}, C_{2}=$ parameters used in derivation

$D \quad=$ diameter of cylinder

$h \quad=$ wall thickness

$\boldsymbol{K}=$ strength coefficient introduced in Equation (1)

$L \quad=$ length of cylindrical portion of pressure vessel

$n=$ strain-hardening exponent introduced in Equation (1)

$P_{a} \quad=$ total axial load

$\boldsymbol{R} \quad=$ true strain ratio defined by Equation (2)

$r \quad=$ radius of cylinder

$S \quad=$ nominal stress

$x, x^{\prime}=S_{\theta i} / S_{t u}$ for the isotropic and texture-hardening cases

$\alpha \quad=$ true strength ratio defined by Equation (4)

$\alpha_{i j} \quad=$ orthotropic parameters of Ref. [10]

$\epsilon \quad=$ true strain

$\overline{\boldsymbol{\epsilon}} \quad=$ effective true strain

$\sigma \quad=$ true stress

$\bar{\sigma} \quad=$ effective true stress defined by Equation (7)

$\mu_{p} \quad=$ Poisson's ratio associated with in-plane plastic strain

\section{Subscripts}

$a=$ axial direction

$F L \quad=$ finite length

fs $=$ filament/substrate composite

$i \quad=$ instability 


\section{Charles W. Bert and Walter S. Hyler}

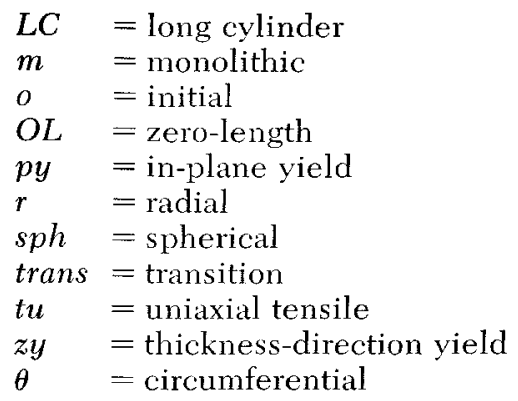

\section{REFERENCES}

1. W. A. Backofen, W. F. Hosford, and J. J. Burke, "Texture Hardening”, Am. Soc. Metals Trans. Quart., Vol. 55 (1962), p. 264.

2. W. F. Hosford, Jr., and W. A. Backofen, "Strength and Plasticity of Textured Metals", Fundamentals of Deformation Processing, Proc. 9th Sagamore Army Materials Research Conference, 1962, Syracuse University Press, Syracuse, New York, (1964), p. 259.

3. R. Hill, "A Theory of Yielding and Plastic Flow of Anisotropic Metals", Proc. Royal Soc. (London) Vol. 193A (1948), p. 281.

4. R. Hill, The Mathematical Theory of Plasticity, Oxford University Press, London (1950), Chapter XII, p. 317.

5. G. Gerard, "Aerospace Pressure Vessel Design Synthesis", NASA CR-287 (Aug. 1965).

6. J. L. Sliney, D. A. Corrigan, and F. Schmid, "Preliminary Report of the Biaxial Tensile Behavior of Anisotropic Sheet Materials", U.S. Army Materials Research Agency, Watertown, Mass., Tech. Rept. 63-11 (Aug. 1963).

7. W. J. Martin, T. Matsuda, and E. F. Kaluza, "Study of Titanium Alloy Tankage at Cryogenic Temperatures", Donglas Aircraft Company, Inc., Missile and Space Systems Division, Santa Monica, Calif., Rept. SM-43116 (May 1964).

8. H. W. Babel, D. A. Eitman, and R. W. McIver, "The Biaxial Strengthening of Textured Titanium", Am. Soc. Mech. Engrs. Paper 66-Met-6 (April 1966).

9. H. W. Babel and C. Y. Kam, "Textured Titanium in Design", AIAA/ASME 7th Structures and Materials Conference, AIAA (April 1966), p. 71.

10. J. Marin, and M. G. Sharma, "Design of a Thin-Walled Cylindrical Pressure Vessel Based Upon the Plastic Range and Considering Anisotropy", Welding Research Council Bulletin No. 40 (May 1958).

11. C. N. Odell, and W. E. Albert, "The Filament-Reinforced Motor Case", Aerospace Engr., Vol. 21, No. 4 (April 1962), p. 52.

12. L. Mayer, "High-Performance, Low-Cost Motor Cases of Aluminum", ARS $J$., Vol. 32 (1962), p. 1044.

13. F. Wolff, and A. Harvey, "Prestressed Fiber-Metal Cylindrical Vessels", Am. Soc. Mech. Engrs. Paper 63-AHGT-70 (March 1963).

14. R. H. Johns and A. Kaufman, "Filament-Overwrapped Metallic Cylindrical Pressure Vessels", AIAA/ASME 7th Structures and Materials Conference, AIAA, (April 1966), p. 52; J. Spacecraft \& Rockets, Vol. 4 (1967) p.872.

15. J. H. Hollomon, "Tensile Deformation", Metals Technology, Vol. 12 (1945) Tech Publ. No. 1879.

16. L. W. Hu, "Studies on Plastic Flow of Anisotropic Metals", Jour. Appl. Mech., Vol. 23 (1956), p. 444.

17. B. Budiansky, "A Reassessment of Deformation Theories of Plasticity", Jour. Appl. Mech., Vol. 26 (1959), p. 259. 


\section{Analysis of Ductile Bursting in Pressure Vessels}

18. J. F. Besselring, "A Theory of Plastic Flow for Anisotropic Hardening in Plastic Deformation of an Initially Isotropic Material", National Aeronautical Research Laboratory (NLL), Amsterdam, Holland, Report S.410 (1953).

19. F. Nakanishi, and Y. Sato, "Anisotropy Due to Plastic Deformation", Proc. 8th Japan Nat. Congr. Appl. Mech., (1958), p. 249. See also Selected Papers of F. Nakanishi, Department of Aeronautics, University of Tokyo, Tokyo, Japan, (1966), p. 156.

20. A. Baltov and A. Sawczuk, "A Rule of Anisotropic Hardening", Acta Mechanica, Vol. 1 (1965), p. 81.

21. L. W. Hu, "Plastic Stress-Strain Relations and Hydrostatic Stress", Plasticity (Proc. 2nd Sympos on Naval Structural Mechanics), Pergamon Press, New York (1960), ed. by E. H. Lee and P. S. Symonds, p. 194.

22. L. W. Hu and K. D. Pae, "Inclusion of the Hydrostatic Stress Component in Formulation of the Yield Condition", Jour. Franklin Inst., Vol. 275 (1963), p. 491.

23. C. W. Bert, E. J. Mills, and W. S. Hyler, "Effect of Variation in Poisson's Ratio on Plastic Tensile Instability", J. Basic Engr., Trans. ASME, Vol. 89D (1967), p. 35.

24. F. R. Larson, "Anisotropy of Titanium Sheet in Uniaxial Tension", Am. Soc. Metals Trans. Quart., Vol. 57 (1964), p. 620.

25. C. W. Bert and W. S. Hyler, "Design Considerations in Material Selection for Rocket-Motor Cases", J. Spacecraft \& Rockets, Vol. 4 (1967), p. 705.

26. F. R. Larson and J. Nunes, "Strain Hardening Properties of High-Strength Sheet Materials", Am. Soc. Metals Trans. Quart., Vol. 54 (1961), p. 481.

27. A. J. Hatch, "Texture Strengthening of Titanium Alloys", Trans. Metallurgical Soc. of AIME, Vol. 233 (1965), p. 44.

28. G. Sachs, L. Schapiro, and O. Hoffman, "Strength of Ductile Metal Motor Cases", Am. Rocket Soc. Paper 2419-62 (April 1962).

29. N. A. Weil, M. A. Salmon, and C. J. Costantino, "Approximate Burst Strength of Thin-Walled Cylinders With Hemispherical Caps", AIAA J., Vol. I (1963), p. 2088.

30. R. P. Felgar, "Plastic Analysis of the Instability of Pressure Vessels Subjected to Internal Pressure and Axial Load", J. Basic Eng., Trans. ASME, Vol. 84D (1962), p. 278.

31. J. Marin, Mechanical Behavior of Engineering Materials, Prentice-Hall, Inc., Englewood Cliffs, New Jersey (1962), p. 31.

32. H. W. Babel and D. L. Corn, "A Comparison of Methods for Correlating Texturing with the Biaxial Strengths of Titanium Alloys", Metals Eng. Quart., Vol. 7 (1967), p. 45.

33. D. Lee and W. A. Backofen, "An Experimental Determination of the Yield Locus for Titanium and Titanium-Alloy Sheet", Trans. Metallurgical Soc. AIME, Vol. 236 (1966), p. 1077.

34. J. L. Sliney, "Biaxial Tensile Behavior of Ti-5Al-2.5Sn Alloy", U.S. Army Materials Research Agency, Watertown, Mass., Tech. Rept. 67-22 (June 1967).

(received February 12, 1968) 